\title{
SAFETY OF USE OF THE BUILDINGS IN THE ASPECT OF THE INDOOR ENVIRONMENTAL QUALITY
}

doi: $\quad 10.2478 /$ czoto-2019-0041

Date of submission of the article to the Editor: 01/12/2018

Date of acceptance of the article by the Editor: 12/02/209

Anna Lis ${ }^{1}$ - orcid id: 0000-0001-9497-5754

Zuzana Vranayova ${ }^{2}$ - orcid id: 0000-0003-1172-6248

${ }^{1}$ Czestochowa University of Technology, Poland, alis@bud.pcz.pl

${ }^{2}$ Technical University of Kosice, Slovakia

Abstract: Safety of use of the buildings refers i.a. to ensuring appropriate hygienic and sanitary conditions and also health conditions. According to the EU Directive on the energy performance of buildings, there is a need to define the conditions for the classification of objects in terms of indoor microclimate requirements. Evaluating the quality of the interior environment in buildings and specifying the requirements of people staying in them, first of all the values of thermal microclimate parameters and air quality should be taken into account. Long-term influence of disadvantageous of environmental conditions may cause or exacerbate many symptoms associated with abnormal functioning of the organism and lead to the weakness or illness. This phenomenon is called sick building syndrome, and the symptoms of the syndrome such as eyes and respiratory tract irritation, malaise, dizziness and headache or fatigue are linked to time spent in the building. The article presents the results of research on the condition of the interior environment in educational buildings, identifies factors affecting the formation of environmental conditions in the rooms and shows the influence of the interiors environment in buildings on the human body. The relationships between the basic parameters of the interior microclimate and the state of feeling satisfaction with the environmental conditions that surrounds the human are tracked. It was found that in many cases commonly used gravitational ventilation is not able to ensure the proper conditions of the interior microclimate, and the concentrations of carbon dioxide recorded in the tested rooms exceeded the applicable standards.

Keywords: interior microclimate, air quality, hygienic and sanitary conditions, sick building syndrome, safety of use of the buildings.

\section{INTRODUCTION}

The problem of the safety of use of rooms in the aspect of the indoor environmental quality in buildings is extremely important because this quality has a considerable impact on the well-being and health of people staying there (Al Horr et al., 2016, Godish, 2016). Due to the fact that people spend up to $80-95 \%$ of our life indoors, buildings should be a structure that will not have a negative impact on their organism. 
Both EU Directive on the energy performance of buildings (Directive, 2018) as well the Polish Construction Law (Act, 2018) and the Technical Conditions (Regulation of the Minister of Infrastructure, 2015) indicate the necessity of ensuring appropriate hygienic and health conditions in the rooms.

Both thermal parameters of the microclimate as well as chemical, microbiological pollutants and air ionization and also ionizing and non-ionizing radiation, lighting and noise have a strong impact on the human body. Deviations from the optimal values of the environmental parameters are conducive to the deterioration of well-being and the emergence of disease states. This phenomenon is called the sick building syndrome (SBS), and its symptoms appear to be closely linked to time spent in the building and decrease or disappear after leaving it (Indoor air pollutants 1983, Terms of Environment 2009, Sick building 1998). Symptoms of the syndrome are primarily eye, nose or throat irritation, itching and dry skin, hoarseness and dry cough, cold and flu-like symptoms, dizziness and headache, nausea, sensitivity to odours, allergies and increased incidence of asthma attacks or fatigue, irritability and difficulty in concentration. Insufficient or improper ventilation contributes to the constant deterioration of air quality in enclosed rooms and intensifying of the syndrome phenomenon, which often refers to new energy-saving or modernized buildings (Sowa, 2015, Sowa ,2018, Januszkiewicz, 2017). The sick building syndrome problem began to be taken seriously when the attention was paid to the relationship between indoor environmental quality and increasing sickness absence and its high economic cost (Economic cost 2015, Evolution of WHO 2017, Indoor air pollutants 1983). It was estimated that the annual economic effects associated with the elimination of the syndrome phenomenon and production growth would amount to $25-60 \%$ compared to the application of other activities not related to improvement of environmental quality. The European Lung Foundation considers, moreover, that indoor air pollution is the 8th most important risk factor for disease and between 1.5 million and 2 million deaths a year may be associated with inadequate indoor environmental quality in the building.

The research on the indoor environmental quality was carried out in educational buildings. The state of the interior environment in this type of buildings affects not only the well-being and health of the people staying there, but also the comfort of work (School environment, 2015). Many studies are focused on indoor environmental quality in educational buildings, i.a. (Dorizas et al., 2015, Haverinen-Shaughnessy, 2015, Mihaia and lordacheb, 2016, Turunen et al., 2014, Indoor air quality, 2012, Vilcekova et al., 2017).

The subject of the conducted research was the assessment of the indoor environmental quality based on selected parameters and its impact on thermal comfort and safety of use of rooms associated with the appearance of symptoms of a sick building syndrome among building users. The measurement of selected parameters was carried out in classrooms of educational buildings located in Czestochowa city during the heating season. The temperature, relative humidity and air velocity in rooms as well as ambient radiation temperature were measured. In addition, the content of $\mathrm{CO}_{2}$ in the air were also measured. The assessment of thermal comfort was based on the Predicted Mean Vote (PMV) and Predicted Percentage Dissatisfied (PPD). SBS symptoms occurring among room users have been determined. The relationships between the examined parameters of the interior microclimate and the state of feeling satisfaction with the environmental conditions have been investigated. 


\section{METHODOLOGY OF RESEARCH}

First of all, the parameters of the microclimate have been measured. Then, the personal factors of the microclimate were followed. Thermal insulation of clothing (IcI) and the value of metabolic energy related to physical activity of individual person (M) were analyzed. In determining the metabolic rate and the thermal insulation of clothing, the values and formulas contained in the literature were used (PN-EN ISO 8996:2005, PN-EN ISO 9920:2009). The $\mathrm{CO}_{2}$ content in the air was determined using VZ8913 Thermoanemometer. PMV and PPD measurements were made with the Brüel \& Kjær thermal comfort meter. The meter allows to determine the state of comfort based on air temperature, its flow rate, average ambient temperature, partial vapor pressure, thermal clothing insulation and metabolic level. PMV and PPD indicators are used for practical assessment of moderate thermal environment on a normalized scale by a large number of people (PN-EN ISO 7730:2006). The obtained value of PMV is compared with a 7-point scale of thermal feelings (Table 1).

Table 1

PMV variability scale

\begin{tabular}{|c|c|c|c|c|c|c|}
\hline-3 & -2 & -1 & $\mathbf{0}$ & $\mathbf{+ 1}$ & $\mathbf{+ 2}$ & $\mathbf{+ 3}$ \\
\hline cold & cool & slightly cool & neutral & slightly warm & warm & hot \\
\hline
\end{tabular}

Source: (PN-EN ISO 7730:2006).

PMV and PPD indicators are applicable when the air temperature in the analyzed room is in the range of $10 \div 30^{\circ} \mathrm{C}$, energy expenditure of people in the range of $0.8 \div 4.0$ met, and thermal insulation of their clothing in the range of $0 \div 2$ clo. The analytical relationship between PPD and PMV is shown in Figure 1.

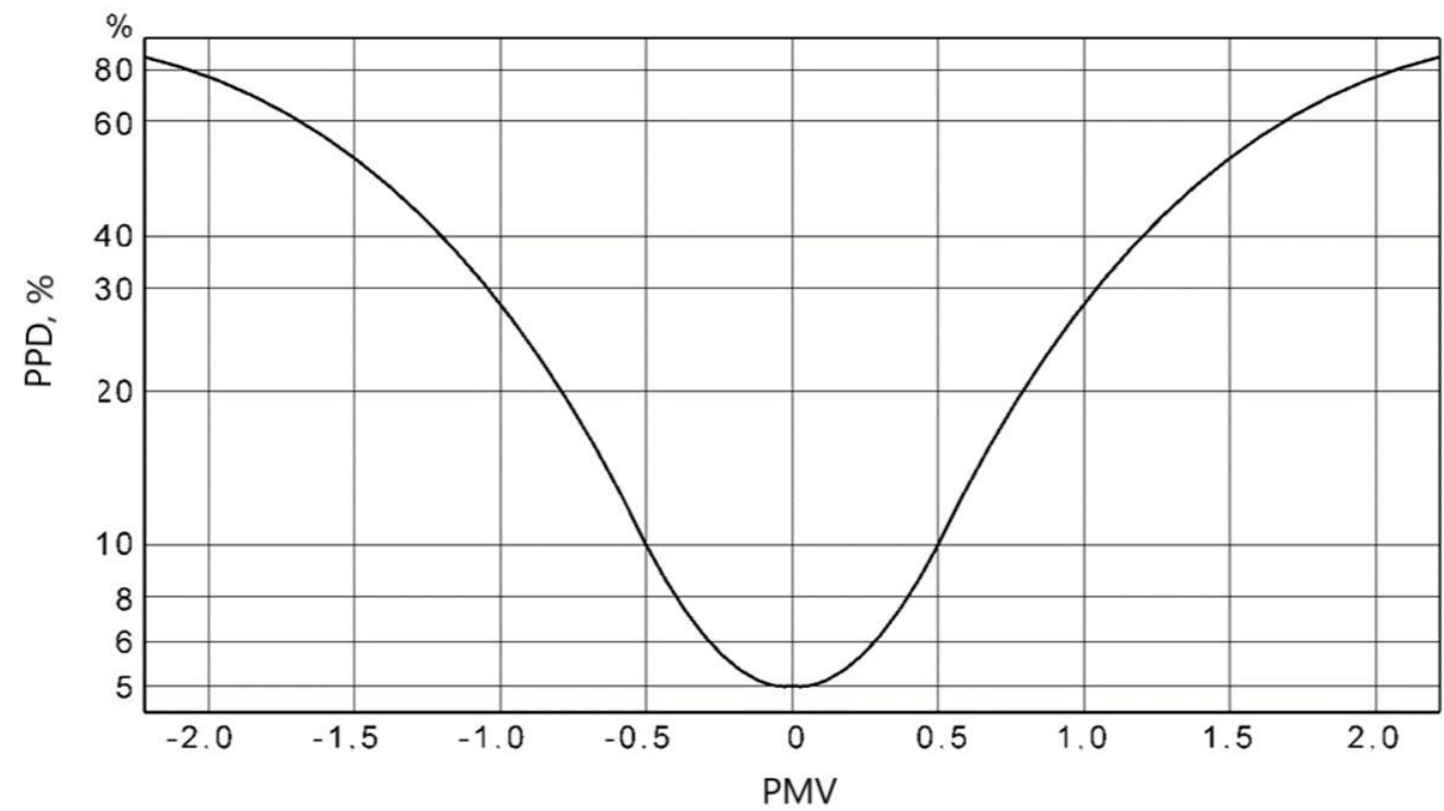

Fig. 1. PPD in PMV function (PN-EN ISO 7730:2006)

When $90 \%$ of people assesses the environment as comfortable, for $5 \%$ is cold or hot. During the research, natural conditions were preserved in the rooms without interfering in the implementation of activities covered by the typical schedule of the day. 


\section{RESULTS}

In the Table 2 are shown average values of air temperature $\left(t_{a}\right)$, relative humidity $\left(\varphi_{a}\right)$, air velocity $\left(\mathrm{v}_{\mathrm{a}}\right)$ and ambient radiation temperature $\left(\mathrm{t}_{\mathrm{r}}\right)$ with standard deviation value (s). For the air velocity, the harmonic mean was determined and for the remaining parameters the arithmetic mean.

Table 2

Thermal microclimate parameters

\begin{tabular}{|c|c|c|c|c|c|c|c|c|c|}
\hline \multicolumn{2}{|c|}{ Parameters } & \multicolumn{2}{|c|}{ Autumn } & \multicolumn{2}{c|}{ Winter } & \multicolumn{2}{c|}{ Spring } & \multicolumn{2}{c|}{ Whole period } \\
\cline { 3 - 10 } & average & s & average & s & average & s & average & s \\
\hline $\mathrm{t}_{\mathrm{a}}$ & ${ }^{\circ} \mathrm{C}$ & 19.2 & 2.4 & 21.3 & 2.8 & 22.1 & 4.2 & 20.4 & 3.4 \\
\hline $\mathrm{t}_{\mathrm{ra}}$ & ${ }^{\circ} \mathrm{C}$ & 19.6 & 2.8 & 21.1 & 2.7 & 22.9 & 4.0 & 21.0 & 3.4 \\
\hline$\varphi_{\mathrm{a}}$ & $\%$ & 35.8 & 10.3 & 21.8 & 8.5 & 31.5 & 11.0 & 29.8 & 11.5 \\
\hline $\mathrm{v}_{\mathrm{a}}$ & $\mathrm{m} / \mathrm{s}$ & 0.11 & 0.07 & 0.05 & 0.02 & 0.10 & 0.05 & 0.09 & 0.05 \\
\hline
\end{tabular}

The air temperature in the rooms was on average $20.4^{\circ} \mathrm{C}$ with the standard deviation equal to $3.4^{\circ} \mathrm{C}$. The ambient radiation temperature in the considered period was about $0.6^{\circ} \mathrm{C}$ higher than the air temperature. The temperature difference between the level of head and feet did not exceed $2.5^{\circ} \mathrm{C}$. The temperature near the floor did not differ by more than about $2.7^{\circ} \mathrm{C}$ from the average air temperature designated for a given room. The value of the relative humidity of the air ranged from 21 to $67 \%$ and amounted to an average of $30 \%$. During the day there was a gradual increase in the humidity value by about $10 \%$. The velocity of air flow in the rooms was maintained at a relatively low level of about $0.1 \mathrm{~m} / \mathrm{s}$ and did not exceed $0.3 \mathrm{~m} / \mathrm{s}$

The $\mathrm{CO}_{2}$ concentration in the rooms changed dynamically. The initial $\mathrm{CO}_{2}$ content in the air was about 500-800 ppm and increased rapidly depending on the number of people in the rooms. Within an hour, this increase was on average $500-600 \mathrm{ppm}$ and even up to 1000-1100 ppm. The largest measured value after about two hours was 3572 ppm. Intensive airing of the rooms caused a rapid drop in $\mathrm{CO}_{2}$ levels.

For the thermal comfort of people in the rooms a significant impact has the thermal insulation of clothing and the level of metabolism. The estimated values of these parameters are presented in Table 3.

Table 3

Personal microclimate parameters

\begin{tabular}{|c|c|c|c|c|c|c|c|c|c|c|}
\hline \multirow{2}{*}{\multicolumn{3}{|c|}{ Parameters }} & \multicolumn{2}{|c|}{ Autumn } & \multicolumn{2}{|c|}{ Winter } & \multicolumn{2}{|c|}{ Spring } & \multicolumn{2}{|c|}{ Whole period } \\
\hline & & & average & $\mathbf{s}$ & average & $\mathbf{s}$ & average & $\mathbf{s}$ & average & $\mathbf{s}$ \\
\hline \multirow{2}{*}{ Pupils } & $I_{\mathrm{cl}}$ & clo & 0.82 & 0.08 & 0.84 & 0.11 & 0.79 & 0.12 & 0.81 & 0.09 \\
\hline & $\bar{M}$ & met & 2.06 & 0.22 & 2.01 & 0.23 & 2.03 & 0.24 & 2.04 & 0.23 \\
\hline \multirow{2}{*}{ Teachers } & $\overline{I_{\mathrm{Cl}}}$ & clo & 0.83 & 0.12 & 0.86 & 0.09 & 0.80 & 0.15 & 0.82 & 0.10 \\
\hline & $\bar{M}$ & met & 1.40 & 0.25 & 1.31 & 0.17 & 1.47 & 0.26 & 1.41 & 0.19 \\
\hline
\end{tabular}

The average thermal insulation of clothing was similar for both groups using the building. In the range of $0.7-0.9$ clo, approximately $88 \%$ of the obtained results were focused. However, a lower level of metabolic energy was recorded in adults, which results from its decline with age. The values of PMV and PPD obtained as a result of the calculations were similar to those obtained during the tests, which allowed the verification of measurement data. In the comfort zone $(-1-+1)$ were $81 \%$ of the value 
of PMV indicators estimated for pupils and $80 \%$ for teachers. About $20 \%$ of room users were dissatisfied with the thermal comfort conditions (Table 4).

Table 4

Thermal comfort evaluation indicators

\begin{tabular}{|l|c|c|c|c|c|c|c|c|c|c|}
\hline \multicolumn{2}{|c|}{ Parameters } & \multicolumn{2}{c|}{ Autumn } & \multicolumn{2}{c|}{ Winter } & \multicolumn{2}{c|}{ Spring } & \multicolumn{2}{c|}{ Whole period } \\
\cline { 3 - 11 } \multicolumn{2}{|c|}{} & & average & s & average & s & average & s & average & s \\
\hline \multirow{2}{*}{ Pupils } & PMV & - & 0.5 & 0.8 & 0.4 & 0.9 & 0.5 & 0.9 & 0.5 & 0.8 \\
\cline { 2 - 11 } & PPD & $\%$ & 25 & 22 & 21 & 20 & 26 & 26 & 23 & 21 \\
\hline \multirow{2}{*}{ Teachers } & PMV & - & -0.5 & 0.7 & -0.5 & 0.8 & -0.4 & 0.7 & -0.4 & 0.8 \\
\cline { 2 - 11 } & PPD & $\%$ & 29 & 20 & 23 & 18 & 19 & 23 & 21 & 20 \\
\hline
\end{tabular}

\section{DISCUSSION}

During the heating season, the temperature in the rooms depends mainly on the heating system's parameters. With a similar level of thermal insulation of clothing, but with different metabolism, both groups of room occupants differed in the range of preferred air temperature considered to be comfortable. For pupils it was $19.6^{\circ} \mathrm{C}$ and for teachers $23.1^{\circ} \mathrm{C}$. During the day rather small fluctuations in the air relative humidity were noted, however, significant fluctuations in its value in the analyzed buildings can be observed during the year. The air flow velocity in the rooms was relatively small, and the occasional excessive infiltration of air through the leaky windows influenced rather the temperature drop and was responsible for the disruption of uniformity of its distribution. The air temperature and the average ambient radiation temperature were the most influential in shaping the values of thermal comfort (Fig 2), while neither relative humidity nor air velocity did not have a significant impact on PMV value.

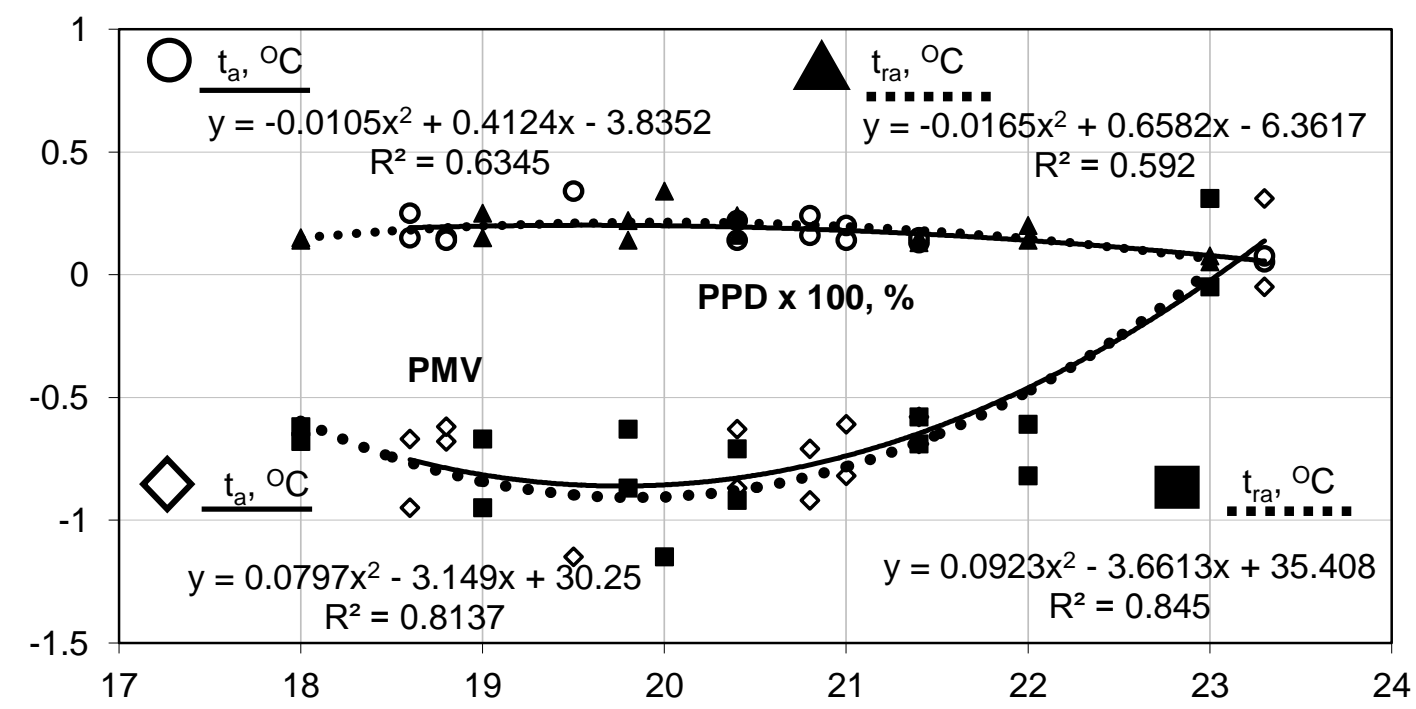

Fig. 2. Influence of temperature and ambient radiation temperature on the value of PMV and PPD

High carbon dioxide concentrations have a negative impact on the human well-being and health (Kapalo et al., 2018). the correct level is 450-1000 ppm. By the level 2000 poor air quality and sleepiness is already observed. At values $2000-5000$ ppm the headaches are possible. Values over 5000 ppm leads to discomfort and rapid heart rate, over 15000 to problems with breathing and over 30000 to dizziness and 
indisposition. Concentration above 60000 may cause a blackout (Kapalo, 2014). The highest permissible concentration in the work environment is $9000 \mathrm{mg} / \mathrm{m}^{3}$ i.e. about 5000 ppm (Regulation of the Minister of Family, 2018). Distribution of concentrations of carbon dioxide (in ppm) in the air over the time is shown in Fig. 3.

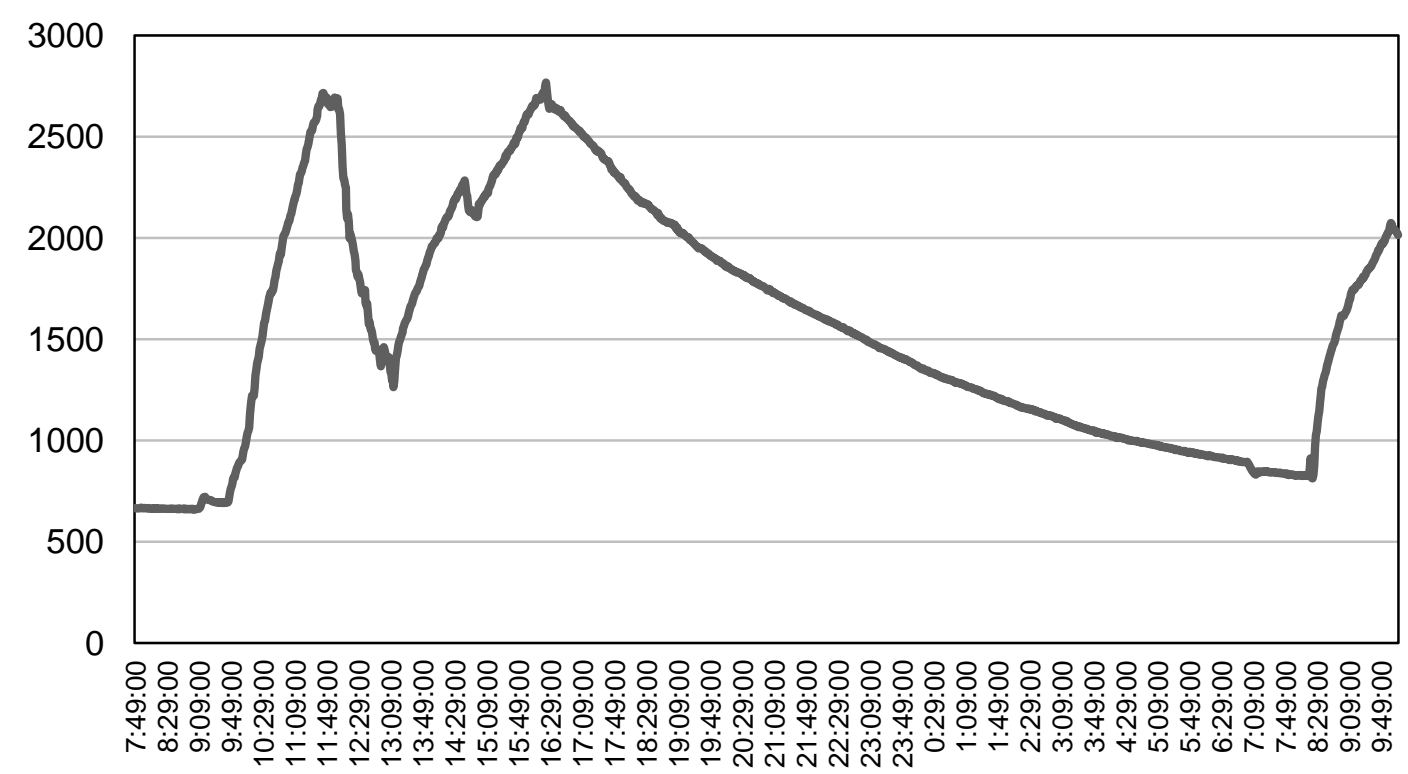

Fig. 3. Distribution of concentrations of carbon dioxide (in ppm) in the air over the time

During the research, the sick building syndrome symptoms were observed in people staying in the rooms, which they identified with long-term staying in a given environment. Increased eye, nose throat irritation, headache, fatigue and sleepiness as well as general poor air quality have been reported on the level of $97 \%$ (Table 5).

Table 5

Sick building syndrome symptoms

\begin{tabular}{|l|c|}
\hline \multicolumn{1}{|c|}{ Sick building syndrome symptoms } & Percent symptom occurrence \\
\hline Eye irritation & 36.2 \\
\hline Nose irritation, rhinitis & 42.0 \\
\hline Itching and dry skin & 3.9 \\
\hline Throat irritation, cough & 46.4 \\
\hline Flu-like symptoms & 29.7 \\
\hline Dizziness and headache & 59.3 \\
\hline Fatigue and sleepiness & 31.3 \\
\hline Irritability & 17.4 \\
\hline Difficulty in concentration & 23.7 \\
\hline Malaise & 17.6 \\
\hline
\end{tabular}

Increasing the number of air exchanges in rooms will reduce the level of $\mathrm{CO} 2$ pollution and eliminate the phenomenon of a sick building (Kapalo et al. 2014). To maintain proper environmental conditions during the operation of the building, it would be good to use tools based on BIM technology (Sobczyk et al., 2018). 


\section{CONCLUSION}

Proper shaping of the values of individual elements of the interior microclimate is a basic condition for the persons staying in a given environment to achieve thermal comfort and general well-being and health.

There was a clear relationship between the air temperature and the average temperature of the ambient radiation and the feeling of thermal comfort. The children preferred lower air temperature in the environment in which they stayed than adults. The value of thermal insulation of clothing was varied and depends on the air temperature in the rooms, the level of metabolism and individual preferences of people staying indoors, as well as stereotyped habits related to the wearing of a particular type of clothing at certain times of the year. The research shows that children in the same environment and at the same physical activity could wear clothing with an insulation of about $30-40 \%$ lower than adults.

The average thermal comfort rating of PMV in the considered environment was within the acceptable comfort zone, but a very low ventilation efficiency can be observed from the curve of the carbon dioxide concentration. Concentrations at 2000-3000 ppm do not ensure the safety of staying in the room. It was found that in many cases commonly used gravitational ventilation was not able to ensure the proper conditions of the interior microclimate, which resulted, not only, in maintaining a high concentration of carbon dioxide but also the appearance of symptoms of the sick building syndrome among users of the rooms. Improvement of the indoor environmental quality through the introduction of mechanical ventilation increases the safety of the building's use.

\section{REFERENCES}

Act of 7th July 1994 the Construction Law (consolidated version: OJ 2018 item. 1202).

Al Horr, Y., Arif, M., Katafygiotou, M., Mazroei, A., Kaushik, A., Elsarrag, E., 2016. Impact of indoor environmental quality on occupant well-being and comfort: $A$ review of the literature. International Journal of Sustainable Built Environment 5(1), 1-11. DOI: $10.1016 /$ j.ijsbe.2016.03.006

Economic cost of the health impact of air pollution in Europe: Clean air, health and wealth, 2015. WHO Regional Office for Europe.

Evolution of WHO air quality guidelines: past, present and future, 2017. WHO Regional Office for Europe, Copenhagen.

Dorizas, P.V., Assimakopoulos, M.N., Santamouris, M., 2015. A holistic approach for the assessment of the indoor environmental quality, student productivity, and energy consumption in primary schools. Environmental Monitoring and Assessment 187, 259. DOI: 10.1007/s10661-015-4503-9

Directive 2018/844/EU of The European Parliament and of the Council of 30 May 2018 amending Directive 2010/31/EU on the energy performance of buildings and Directive 2012/27/EU on energy efficiency.

Godish, T., 2016. Indoor environmental quality. Lewis Publishers, Boca Raton, London New York Washington.

Haverinen-Shaughnessy, U., Shaughnessy, R.J., Cole, E.C., Toyinbo, O., Moschandreas D.J., 2015. An assessment of indoor environmental quality in schools and its association with health and performance. Building and Environment 9(1), 35-40. DOI: 10.1016/j.buildenv.2015.03.006. 
Januszkiewicz, K., 2017. The health protective and energy saving urban environment at the time of climate change. Budownictwo o zoptymalizowanym potencjale energetycznym, 2(20), 43-50. DOI: 10.17512/bozpe.2017.2.06

Indoor air pollutants: exposure and health effects, EURO Reports and Studies, 1984. World Health Organization.

Indoor air quality tools for schools: High performance schools, 2012. United States Environmental Protection Agency.

Kapalo, P., Domniţa, F., Bacoţiu, C., Spodyniuk, N., 2018. The impact of carbon dioxide concentration on the human health - case study. Journal of Applied Engineering Sciences 8(21), 61-66. DOI: 10.2478/jaes-2018-0008

Kapalo, P., Sedláková, A., Košicanová, D., Voznyak, O., Lojkovics, J., Siroczki, P., 2014. Effect of ventilation on indoor environmental quality in buildings. The 9th International Conference on Environmental Engineering Selected Papers, Vilnius, VGTU Press, 1-6. DOI: 10.3846/enviro.2014.265

Mihaia, T., lordacheb, V., 2016. Determining the indoor environment quality for an educational building. Energy Procedia 85, 566-574. DOI: 10.1016/j.egypro.2015.12.246.

PN-EN ISO 7730:2006, Ergonomics of the thermal environment - Analytical determination and interpretation of thermal comfort using calculation of the PMV and PPD indices and local thermal comfort criteria.

PN-EN ISO 8996:2005, Ergonomics of the thermal environment - Determination of metabolic rate.

PN-EN ISO 9920:2009, Ergonomics of the thermal environment - Estimation of thermal insulation and water vapour resistance of a clothing ensemble.

Regulation of the Minister of Family, Labour and Social policy of 12th June 2018 on maximum permissible concentration and intensity of agents harmful to health in the working environment (OJ 2018, item. 1286).

Regulation of the Minister of Infrastructure of 12th April 2002 on technical conditions, which should correspond to the buildings and their location (consolidated version: OJ 2015 item. 1422, as amended OJ 2017 item. 2285).

School environment: policies and current status, 2015. WHO Regional Office for Europe. Sick building syndrome, 1998. World Health Organization Regional Office for Europe.

Sobczyk, A., Pobędza, J., Sobczyk, M., 2018. Improvement of quality by using an integrated management system of construction processes, MATEC Web of Conferences 183. DOI: $10.1051 /$ matecconf $/ 201818303010$

Sowa, J., 2018. Jakość powietrza w budynkach modernizowanych. Izolacje 23(2), 76-82.

Sowa, J., 2015. Jakość powietrza w budynkach energooszczędnych, (w:) Budownictwo energooszczędne w Polsce - stan i perspektywy, Red.: M. Wesołowska, Wydawnictwo Uczelniane Uniwersytetu TechnologicznoPrzyrodniczego, Bydgoszcz, 155-166.

Terms of Environment, 2009. United States Environmental Protection Agency, USA.

Turunen, M., Toyinbo, O., Putus, T., Nevalainen, A.,, Shaughnessy, R., HaverinenShaughnessy, U., 2014. Indoor environmental quality in school buildings, and the health and wellbeing of students. International Journal of Hygiene and Environmental Health 217(7), 733-739. DOI: 10.1016/j.ijheh.2014.03.002.

Vilcekova, S., Kapalo, P., Meciarova, L., Krídlová Burdová, E., Imreczeova, V., 2017. Investigation of Indoor Environment Quality in Classroom - Case Study. Procedia Engineering 190, 496-503. DOI: 10.1016/j.proeng.2017.05.369. 